\title{
The influences of SE infection on layers' production performance, egg quality and blood biochemical indicators
}

\author{
Shijie Fan ${ }^{\dagger}$, Jiangxia Zheng ${ }^{\dagger}$, Zhongyi Duan, Ning Yang and Guiyun Xü
}

\begin{abstract}
Background: Salmonella enterica serovar Enteritidis (SE), as a major cause of foodborn illness, infects humans mainly through the egg. However, the symptom of laying hens usually is not typical and hard to diagnosis. In the present study, it is studied that the influences of SE infection on layers' performance, egg quality and blood biochemical indicators. It will help us to improve the strategy to control SE infection in commercial layers. One hundred layers at 20 wk of age were divided into 2 groups, 60 hens for experiment and others for control. The experiment group was fed with the dosage of $10^{8}$ CFU SE per hen. The specific PCR was used to detect the deposition of SE. On the $8 \mathrm{~d}$ after SE infection, 10 hens from the control group and 30 hens from the experimental group were slaughtered to detect the SE colonization. The production performance, egg quality and blood biochemical indices were also analyzed.

Results: The results showed that the colonization rate of SE was highest in caecum contents (55.17\%) and lowest in vagina (17.24\%). For the eggs the detection rate of SE was highest on the eggshell (80.00\%) and lowest in yolk (18.81\%). SE infection had no significant influence on production performance and egg qualities $(P>0.05)$. The difference of laying rate between the experimental and control groups was less than $0.30 \%$, and both were approximately equal to $82.00 \%$. The blood analysis showed that the aspartic aminotransferase (AST) and alanine aminotransferase (ALT) of experimental group was significantly higher than those of control group $(P<0.05)$. For experimental and control groups AST values were $236.22 \mathrm{U} / \mathrm{I}$ and $211.84 \mathrm{U} / \mathrm{I}$ respectively, and ALT values were $32.19 \mathrm{U} / \mathrm{I}$ and $24.55 \mathrm{U} / \mathrm{l}$. All of coefficients were less than $20 \%$. The colonization of SE in organs increases the enzyme activities of AST and ALT in blood.

Conclusions: SE in feed could invade the oviduct and infect the forming eggs. It significantly increased the concentration of ALT and AST in blood. However,SE infection was hard to be observed from the appearances of layer and egg. It might be a dangerous risk to human health.
\end{abstract}

Keywords: Blood biochemical indicators, Chicken, Egg quality, Salmonella enterica serovar Enteritidis

\section{Background}

In the late 1970s, poultry flocks infected by Salmonella enterica serovar Enteritidis (SE), which was asymptomatic, was reported [1]. By the mid 1980s, SE spread rapidly throughout the United Kingdom, the United States, South America, and other countries [2,3]. Bäumler et al. and Rabsch et al., attributed this to successful campaigns

\footnotetext{
*Correspondence: ncppt@cau.edu.cn

${ }^{\dagger}$ Equal contributors

Department of Animal Genetics and Breeding, National Engineering

Laboratory for Animal Breeding, MOA Key Laboratory of Animal Genetics and Breeding, China Agricultural University, Beijing 100193, China
}

to eradicate the Salmonella serovars Gallinarum $[4,5]$. Which had became a major cause of foodborn illness. Contaminated chicken eggs are an importance agent for the transmission of SE to humans [6-9], especially from consuming eating raw shell eggs and inadequately cooked eggs $[10,11]$. The risk of human infections following consumption of SE-contaminated eggs depends on the bacterial number present [12]. An egg-associated SE outbreaked in US in 2010, led to a nationwide recall of more than 500 millions eggs with nearly 2,752 reported illnesses [11]. Egg contamination issues affected not only public health but also the food industry itself, causing costly

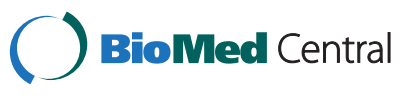


recalls and damage to the reputations of brand-name products [13].

$\mathrm{SE}$ is considered as the only bacterium that routinely causes human infection through intact chicken eggs $[9,14]$. Although an egg has its own protection mechanisms including both physical and chemical barriers, with bactericidal factors such as lysozyme, ovotransferrin, nuclease and $\beta$-defensin-11existed in egg albumen that can kill most bacteria. However, SE has a series of unique mechanisms to survive and multiply in the internal egg contents [11].

Two possible routes of egg contamination by SE, include the colonized gut where contaminated feces can penetrate the eggshell during or after ovipositing (horizontal transmission). Another involves infected reproductive organs that contaminate egg contents directly before ovipositing (vertical transmission or transovarian transmission). Several lines of evidence support the view that egg are mainly contaminated with SE through the vertical transmission. That is SE could escape the host defense and colonize in the reproductive organs including the ovaries and oviduct and thus contaminate the yolk and albumen directly before oviposition [15-17]. Because SE could colonize all sites in the hen reproductive tract, contamination of any part of the egg is possible and environmental hygiene, bacteria vectors such as birds, flies, rodent, and beetles along with feed contamination can be major causes of SE colonization in hens, and thus to eggs.

Although various control measures had been adopted throughout the food production chain, the microbiological testing of eggs during production and processing remain an important role in preventing food-borne infection [18]. However, the traditional cultural isolation method for detecting SE requires up to $5 \mathrm{~d}$ to $7 \mathrm{~d}$ and thus delays diagnosis. Methodology based on PCR is simple, rapid, and specific with high sensitivity. Although it is competent for fast identification and detecting pathogenic microorganisms, including SE, PCR method egg is dependent on specific genes and primers. SE and some other serovars, such as Dublin and Pullorum, the two closest relatives of SE, shared remarkable similarities in both linear organization and sequence of the genomes, with sequence homologies of the conserved regions ranging from 96\% to 99\% $[19,20]$. Moreover SE still could differ significantly from another serovar in several characteristics including specific genes [21]. For example, a unique $60-\mathrm{kb}$ virulence plasmid of SE possesses the Prot6E gene whose encoding has a unique surface fimbriae specific to SE $[21,22]$. The fimbriae played a role in the interaction with egg albumen components. Malorny et al. proved the specificity of Prot6E with 54 serovars [23].

In a previous study, we had tested the specificity of Prot6E in poultry and egg samples, and developed a fast and sensitive PCR method for specific detection of SE.
In the present study, we focused on the colonizing role of SE in hen organs and forming eggs (internal eggs before they were laid), by feeding the egg-laying hens with the feed contaminated by SE.

\section{Methods}

\section{Salmonella strain}

Salmonella enterica ssp. enterica serovar Enteritidis (S. Enteritidis) obtained from China Institute of Veterinary Drugs Control.

\section{Birds}

One hundred SE negative hens were randomly divided into 2 groups, 40 to control group, 60 to experimental group and transferred to two isolation rooms, where they were housed in individual standard wire mesh cages. Blood was obtained from the brachial vein of 20-wk-age White Leghorns hens came from China Agricultural University (CAU), and assayed for SE by the whole-blood plate agglutinate test [24]. Animals were handled in accordance with the principles and procedures outlined by the China Agricultural University's Animal Care and Use Committee.

\section{Feed}

Feed purchased from China Chia Tai Feed Co., Ltd. Consist of cereal, bran, soybean meals, rapeseed meal, fish meal, calcium hydrophosphate, vitamin A, D, E, K, B, minor element including $\mathrm{Cu}, \mathrm{Fe}, \mathrm{Mn}, \mathrm{Zn}$. The percentage of the main feed ingredients as follows, moisture $13.0 \%$, crude protein $16.5 \%$, crude fibre $5.0 \%$, crude ash $13.0 \%$, calcium $3.60 \%$, gross phosphorus $0.65 \%$, salt $0.34 \%$, methionine and cystine $0.68 \%$.

Before and after the experiment, six $15 \mathrm{~g}$ samples of feed were randomly taken from every bag, and enriched successively with cultured bacteria Buffer Peptone Water (BPW) and Selenite Cystine Broth (SC). Using PCR extract bacterial DNA were used to detect whether the feed was contaminated by SE. The results showed that the feed without artificial infection did not contain SE, which would ensure the real SE infection level for the experiment.

\section{Primers design, DNA preparation and DNA amplification}

The sequences of the primer pairs used for PCR detecting were designed according to the SE special Prot6E nucleotide sequence (NO. U66901), the production size was $175 \mathrm{bp}$. The sequences of the primer pairs were as follows: Prot6E-F: 5' -ACAGGGGCACAATAACCGTA3' and Prot6E-R: 5'-TGCATCCCTGTCACAACATT-3'.

Every sample was put in a culture plate and homogenized with BPW according the rate 1:9, and incubated at $37^{\circ} \mathrm{C}$ for $24 \mathrm{~h}$ to allow for bacterial growth. After incubation, injecting $1 \mathrm{ml}$ of the preenrichment broth into 
$9 \mathrm{~mL}$ of SC and incubated at $37^{\circ} \mathrm{C}$ for $24 \mathrm{~h}$. Then, $1 \mathrm{ml}$ of the selective enriched sample was transferred to a microcentrifuge tube with a capacity of $2 \mathrm{~mL}$. The cell suspension was centrifuged for $5 \mathrm{~min}$ at 12,000 rpm. The supernatant was discarded, and then the pellet was washed twice by $\mathrm{ddH}_{2} \mathrm{O}$, and suspended in $200 \mu \mathrm{L} \mathrm{ddH}_{2} \mathrm{O}$. The micro-centrifuge tube was boiled for $15 \mathrm{~min}$ and immediately chilled on ice for $2 \mathrm{~min}$. Then the tube was centrifuged for $15 \mathrm{~min}$ at 12,000 rpm. The supernatant was then transferred to a new micro-centrifuge tube and used as the template DNA in the PCR.

The amplification reaction was performed in a total volume of $15 \mu \mathrm{L}$ as follows: $1.5 \mu \mathrm{L}$ of $10 \times$ PCR buffer, $0.8 \mu \mathrm{L}$ of dNTP, $0.15 \mu \mathrm{L}$ of primer Prot6E-F and $0.15 \mu \mathrm{L}$ of primer Prot6E-R, $1.0 \mu \mathrm{L}$ of DNA, $0.3 \mu \mathrm{L}$ of Ex Taq enzyme, $11.1 \mu \mathrm{L}$ of ddH2O. The reaction mixture was run online at $94^{\circ} \mathrm{C}$ for $5 \mathrm{~min}$, followed by 35 cycles at $94^{\circ} \mathrm{C}$ for $40 \mathrm{~s}, 60^{\circ} \mathrm{C}$ for $40 \mathrm{~s}, 72^{\circ} \mathrm{C}$ for $50 \mathrm{~s}$, with an extension phase of $1 \mathrm{cycle}$ at $72^{\circ} \mathrm{C}$ for $10 \mathrm{~min}$. Samples were fractionated by $1.5 \%$ agarose gel electrophoresis and visualized by ethidium bromide staining.

\section{Supplementary SE to hens}

Two wks pretest were set to record the laying rate (LR) and egg weight (EW) to ensure they were similar on the first day of experiment, the hens in experimental group were fed with $30 \mathrm{~g}$ feed contaminated $9.8 \times 10^{8} \mathrm{CFU}$ SE, the control group hens were fed the feed without SE. Then two groups were fed the feed without SE and raised in the same situation.

\section{Detecting SE in internal organs, reproductive tract and forming eggs}

On the $8 \mathrm{~d}$ and $16 \mathrm{~d}$ after supplementary SE, 10 hens from the control group and 30 hens from the experimental group were euthanized by intravenous injection of T61, and anatomized respectively. Cecal contents, heart, liver, spleen, follicle, ovary, oviduct including infundibulum, magnum, isthmus, uterus, vagina, and forming eggs in the oviduct were collected, and the colonizing of SE evaluated by PCR. The SE on eggshell were sampled and processed within $24 \mathrm{~h}$. Results were showed in Table 1.

\section{Measured blood biochemical indices, production performance and egg qualities}

Blood from the brachial vein were collected in the $8 \mathrm{~d}$ and $16 \mathrm{~d}$ after supplementary SE, and blood biochemical indices, including alanine aminotransferase (ALT), aspartic aminotransferase (AST), lactic dehydrogenase (LDH), glucose (GLU) and total protein (TP) determinal.

Fourteen d before supplementary SE (pretest) and $16 \mathrm{~d}$ after supplementary SE, laying rate and egg weight were recorded daily. Eggshell strength (ESS), eggshell thickness (EST) and eggshell ratio (ESR) were measured daily
Table 1 Colonization rate (\%) of SE in tissues and forming eggs

\begin{tabular}{lcccccc}
\hline & \multicolumn{2}{c}{$\mathbf{8} \mathbf{d}$} & & \multicolumn{2}{c}{$\mathbf{1 6} \mathbf{d}$} \\
\cline { 2 - 3 } \cline { 5 - 6 } Location & Controls & Experiments & & Controls & Experiments \\
Caecum content & 0 & 55.17 & & 0 & 33.33 \\
Heart & $\mathbf{1 0}$ & $\mathbf{3 0}$ & & $\mathbf{1 0}$ & $\mathbf{3 0}$ \\
Liver & 0 & 31.03 & & 0 & 33.33 \\
Spleen & 0 & 44.48 & & 0 & 30.00 \\
Follicle & 0 & 13.79 & & 0 & 36.67 \\
Ovary & 0 & 20.69 & & 0 & 23.33 \\
Infundibulum & 0 & 24.14 & & 0 & 23.33 \\
Magnum & 0 & 24.14 & & 0 & 26.00 \\
Isthmus & 0 & 24.14 & & 0 & 23.33 \\
Uterus & 0 & 31.03 & & 0 & 26.67 \\
Vagina & 0 & 17.24 & & 0 & 23.33 \\
Egg yolk & 0 & 18.81 & & 0 & 14.81 \\
Egg albumen & 0 & 22.73 & & 0 & 22.22 \\
Eggshell membrane & 0 & 40.91 & 0 & 37.50 \\
Eggshell & 0 & 80.00 & 0 & 62.50 \\
\hline
\end{tabular}

for $16 \mathrm{~d}$ after supplementary SE. Data were on the individual bird basis.

\section{Statistical analysis}

The units for analysis were the average values for each hen. All statistical analyses were performed using SAS procedures, $t$-test (SAS Institute, Cary, NC, USA).

\section{Results}

The colonization of SE in hens and forming eggs

After hen was infected by SE, the colonization rate of SE was highest in caecum contents, followed by visceral organs, and lowest in reproductive tract (Table 1). Among the visceral organs, the positive rate was highest in spleen, and the spleen was tumefaction obviously, its weight was significhantly heavier than the control group $(P<0.05)$ (Table 2).

In the reproductive tract, the colonization rate of SE was highest in uterus, moderately high in isthmus and magnum, and lowest in follicles. For the forming eggs, the detection rate of SE was highest on eggshell, followed

Table 2 Effect of SE infection on the chicken's spleen weight

\begin{tabular}{lcc}
\hline Date & \multicolumn{2}{c}{ Spleen weight, $\mathbf{g}$} \\
\cline { 2 - 3 } & Controls, $\mathbf{N}=\mathbf{1 0}$ & Experiments, $\mathbf{N}=\mathbf{3 0}$ \\
\hline $8 \mathrm{~d}$ & $1.24 \pm 0.32^{\mathrm{b}}$ & $1.52 \pm 0.33^{\mathrm{a}}$ \\
$16 \mathrm{~d}$ & $1.22 \pm 0.32^{\mathrm{b}}$ & $1.63 \pm 0.62^{\mathrm{a}}$ \\
\hline
\end{tabular}

${ }^{\mathbf{a}, \mathbf{b}}$ Means in same row with a day lacking a common superscript differ significantly $(P<0.05)$. 
Table 3 Effect of SE infection on the blood biochemical indices

\begin{tabular}{lllll}
\hline & \multicolumn{2}{c}{$\mathbf{8 d}$} & & \multicolumn{2}{c}{$\mathbf{1 6 \mathbf { d }}$} \\
\cline { 2 - 3 } Items & Control & Experiment & & Control \\
\hline $\mathrm{AST}, \mathrm{U} / \mathrm{L}$ & $211.84 \pm 31.63^{\mathrm{a}}$ & $236.22 \pm 33.37^{\mathrm{b}}$ & $269.04 \pm 39.51^{\mathrm{a}}$ & $308.91 \pm 33.93^{\mathrm{b}}$ \\
$\mathrm{ALT}, \mathrm{U} / \mathrm{L}$ & $24.55 \pm 7.55^{\mathrm{a}}$ & $32.19 \pm 10.31^{\mathrm{b}}$ & $22.70 \pm 7.05^{\mathrm{a}}$ & $32.37 \pm 13.73^{\mathrm{b}}$ \\
$\mathrm{GLU}, \mathrm{mmol} / \mathrm{L}$ & $10.83 \pm 0.77$ & $10.91 \pm 0.55$ & $10.28 \pm 0.69$ & $10.46 \pm 0.98$ \\
$\mathrm{LDH}, \mathrm{U} / \mathrm{L}$ & $174.80 \pm 36.99$ & $160.22 \pm 63.07$ & $211.27 \pm 62.73$ & $191.10 \pm 55.63$ \\
$\mathrm{TP}, \mathrm{g} / \mathrm{L}$ & $60.38 \pm 7.23$ & $60.79 \pm 7.65$ & $61.58 \pm 5.15$ & $61.78 \pm 7.96$ \\
\hline
\end{tabular}

${ }^{\mathbf{a}, \mathbf{b}}$ Means in same row for each age lacking a common superscript differ significantly $(P<0.05)$.

by eggshell membrane, albumen, and lowest in and yolk. This pattern was consistent with the colonize tendency in the corresponding site of the reproductive tract.

\section{Blood biochemical indices}

The blood analysis suggested that the AST and ALT of experimental group was significantly higher than that of control group $(P<0.05)$ (Table 3$)$. The GLU, LDH and TP of experimental group were similar to that of controls $(P>0.05)$.

\section{Laying rate and egg quality}

The laying rates and egg weight of controls and experiments were similar during the $14 \mathrm{~d}$ pretest, and then the SE infection didn't influence two traits $(P>0.05)$ (Table 4$)$.

Egg thickness, eggshell strength, eggshell weight and eggshell ratio of experimental group were all lower than that of the controls $(P<0.05)$ (Table 4$)$.

\section{Discussion}

It is well known that traditional cultural isolation of SE is labrious and time-consuming and PCR methods were introduced in the 1990 as simple and faster methods to detect pathogenic microorganisms. The Prot6E gene had been reported as specific for SE, it located on a $60-\mathrm{kb}$ virulence plasmid which was important in the pathogenicity of SE strains [25]. In our previous study, a pair of special primers tested the specificity of Prot6E gene, and showed that the PCR assay was selectivity, accuracy, and applicable. This PCR assay could be used to identify SE or to detect SE directly from poultry tissues or eggs [26].

After hens consumed the feed contaminated by SE, SE entered into esophagus, invaded and passed through intestinal epithelial cell, entered the mesenteric lymph nodes, then spread around the body carried by macrophages. SE could infect and colonize in the spleen, liver, heart, bone marrow and other organs and organizations [16,27-29]. The detection of SE was highest in cecal contents, followed by visceral organs, and lowest in reproductive tract, was consistent with previous researches [30,31]. Among internal organs, the colonization rate in spleen was highest, the reason might be the spleen played a role in filtering blood, and SE spread within the host carried by the macrophages. When SE reached to spleen, huge amounts of macrophages with SE could invade into the spleen tissue. Because of its capability to infiltrate, survive and replicate in the immune cells [31], SE could stimulate the macrophages and lymphocyte to proliferate, resulting in the spleen congestion and tumefaction. The colonization rate of SE in heart and liver was same high, and damage their functions, which could be reflected by the significantly rise of the concentration of ALT and AST. ALT mainly existed in liver cells and is closely related to liver cell activity. AST mainly existed in heart, followed by liver. When the heart and liver are damaged badly, the level of ALT and AST could increase significantly [32].

SE could invade and colonize in each part of oviduct. Starting from the ovary, the infundibulum captured the ovulatory follicles, the magnum produced the albumen, the isthmus deposited the eggshell membranes, the uterus forms the eggshell and the vagina was involved in oviposition. Colonizing of SE in the oviduct might be infect the yolk, albumen, eggshell membrane and eggshell accompanying the egg formation $[31,33,34]$. The infection would not end the formation process of eggs, while SE would not be killed by the antibacterial substances secreted by oviduct. This implied that SE has internal factors or induces factors to counteract the chicken's antibacterial system, and shown a unique live mechanism in the egg formation process.

SE passed serial passage from the liver to spleen, and does not affect its ability to induce egg contamination. However, the repeated in vivo passages in the reproductive

Table 4 Mean and standard deviation for eggshell quality

\begin{tabular}{lcc}
\hline Trait & Controls & Experiments \\
\hline Laying rate, \% & $82.44 \pm 4.45$ & $82.19 \pm 4.12$ \\
Egg weight, g & $41.79 \pm 3.47$ & $42.54 \pm 3.69$ \\
Egg thickness, mm & $0.314 \pm 0.024$ & $0.308 \pm 0.023$ \\
Eggshell strength, $\mathrm{kg} / \mathrm{cm}^{2}$ & $3.325 \pm 0.570$ & $3.174 \pm 0.561$ \\
Eggshell weight, g & $4.76 \pm 0.37$ & $4.72 \pm 0.45$ \\
Eggshell ratio, \% & $11.53 \pm 0.84^{\mathrm{a}}$ & $11.15 \pm 0.67^{\mathrm{b}}$ \\
\hline
\end{tabular}

${ }_{\mathbf{a}, \mathbf{b}}$ Means in same row with lacking a common superscript differ significantly $(P<0.05)$. 
tissues could enhance the ability of SE to cause egg contamination [35]. The results of our study showed that after supplementary SE to hens, the colonization rate of SE in different sites of the reproductive tissues was changed. The colonization rates in follicle, ovary, infundibulum were relatively low, while the colonization rate in uterus was comparatively high. This could lead to the significant differences in contamination rates of SE in different components of the egg.

In this study, The detection of SE in eggshell was highest, moderately high in eggshell membrane and albumen, and the detection in yolk was lowest, which was basically consistent with the colonization rate in the corresponding segment of oviduct. The colonization rate in uterus was obviously higher than other segments, consisting with the higher SE comtamination on the eggshell. However, the colonization rates were not same level. For example, the detection of SE of eggshell was higher than that in uterus. There were some reasons might explain this phenomenon. The SE on the eggshell came not only from colonization in uterus, but also may be influenced by colonization in vagina which could ascend to uterus [36]. The detection of SE in eggshell membrane was higher than that of isthmus. It reflected that eggshell membrane contamination does not only caused by the directly contaminated by SE colonization in isthmus, but also SE in albumen might adhere to eggshell membrane, and SE on eggshell might penetrate onto the membrane. The detection of SE in egg albumen can be lower than that of magnum. The $\mathrm{pH}$ of the egg albumen was alkaline [37], and the albumen contains antibacterial factors including nuclease, lysozyme, ovotransferrin and $\beta$-Defensin-11 [38-41], they could forbid or kill SE [9]. The detection rate in egg yolk was lower than that of ovary. Other studies have suggested that SE had the ability to penetrate into the yolk, when it combine with type 1 fimbriae on vitelline membrane [33,42]. However, the vitelline membrane also had the same antibacterial factors as in albumen [43].

Simulation experiments had shown that various bacterial species could cause internal contamination of egg [44-46]. Under normal production and storage conditions, this was a rare event. When eggs had been damaged or cracked, they could be contaminated by bacteria and deteriorated quickly and could be easily identified. In our study, after supplementary SE to hens, SE colonized in the oviduct and contaminated the forming eggs. The large number of SE colonized in uterus might influence eggshell qualities, although the contamination of the egg contents didn't lead to an abortive egg formation. The egg weight, eggshell strength, eggshell thickness and eggshell weight didn't change by SE contamination. One study observed the growth of SE in eggs did not lead to phenotypic changes in the color, smell and consistency of the egg contents [47]. However, SE kept growing in albumen after eggs output, and it also might penetrate into yolk [48-50].

\section{Conclusions}

In the present study, we designed a specific PCR to test the SE contamination in feed, organ and egg. The chicken infected with SE through feed had no significant changes on production performance and egg qualities. So the laid eggs infected by SE were hard to be discerned by the consumer and became seriously risk to human health.

\section{Competing interests}

The authors declare that they have no competing interests.

\section{Authors' contributions}

FS carried out the experiments and drafted the manuscript. JZ undertook the part of research and wrote the manuscript for publication. GX advised FS in designing and performing the experiment. DZ and NY provided a lot of help with the project. All authors have read and approved the final manuscript.

\section{Acknowledgements}

This study was supported by National System for Layer Production Technology of China (CARS-41), Program for Changjiang Scholars and Innovative Research Team in University of Ministry of Education of China "Study on Poultry Eggs and Meat Detection Technology" (IRT0945) and Chinese Universities Scientific Fund (2013QJ069).

Received: 11 September 2013 Accepted: 31 December 2013

Published: 9 January 2014

\section{References}

1. Agron PG, Walker RL, Kinde H, Sawyer SJ, Hayes DC, Wollard J, Andersen GL: Identification by subtractive hybridization of sequences specific for salmonella enterica serovar enteritidis. Appl Environ Microbiol 2001, 67:4984-4991.

2. Patrick ME, Adcock PM, Gomez TM, Altekruse SF, Holland BH, Tauxe RV, Swerdlow DL: Salmonella enteritidis infections, United States, 1985-1999. Emerg Infect Dis 2004, 10:1-7.

3. Ward LR, Threlfall J, Smith HR, O'Brien SJ: Salmonella enteritidis epidemic. Science 2000, 287:1753

4. Bäumler AJ, Hargis BM, Tsolis RM: Tracing the origins of salmonella outbreaks. Science 2000, 287:50-52.

5. Rabsch W, Hargis BM, Tsolis RM: Competitive exclusion of salmonella enteritidis by salmonella gallinarum in poultry. Emerg Infect Dis 2000, 6:443-448.

6. Braden CR: Salmonella enterica serotype enteritidis and eggs: a national epidemic in the United States. Clin Infect Dis 2006, 43:512-517.

7. Gomez TM, Motarjemi Y, Miyagawa S, Kaferstein FK, Stohr K: Foodborne salmonellosis. World Health Stat Q 1997, 50:81-89.

8. Hope BK, Baker R, Edel ED, Hogue AT, Schlosser WD, Whiting R, McDowell RM, Morales RAL: An overview of the salmonella enteritidis risk assessment for shell eggs and egg products. Risk Anal 2002, 22:203-218.

9. Kang H, Loui C, Clavijo RI, Riley LW, Lu S: Survival characteristics of salmonella enterica serovar enteritidis in chicken egg albumen. Epidemiol Infect 2006, 134:967-976.

10. Gillespie IA, O'Brien SJ, Adak GK, Ward LR, Smith HR: Foodborne general outbreaks of salmonella enteritidis phage type 4 infection, England and Wales, 1992-2002: where are the risks? Epidemiol Infect 2005, 133:795-801.

11. Zhang W, Zheng JX, Xu GY: Toward better control of salmonella contamination by taking advantage of the egg's self-defense system: a review. J Food Sci 2011, 76:R76-R81.

12. Gantois I, Ducatelle R, Pasmans F, Haesebrouck F, Gast R, Humphrey TJ, Immerseel FV: Mechanisms of egg contamination by salmonella enteritidis. FEMS Microbiol Rev 2009, 33:718-738.

13. Techathuvanan C, D'Souza DH: Reverse-transcriptase loop-mediated isothermal amplification as a rapid screening/monitoring tool for salmonella enterica detection in liquid whole eggs. J Food Sci 2012, 77:M200-M205. 
14. Wang L, Mustapha A: EMA-real-time PCR as a reliable method for detection of viable salmonella in chicken and eggs. J Food Sci 2010, 75:M134-M139.

15. Okamura M, Miyamoto T, Kamijima Y, Tani H, Sasai K, Baba E: Differences in abilities to colonize reproductive organs and to contaminate eggs in intravaginally inoculated hens and in vitro adherences to vaginal explants between salmonella enteritidis and other salmonella serovars. Avian Dis 2001, 45:962-971.

16. Okamura M, Kamijima Y, Miyamoto T, Tani H, Sasai K, Baba E: Differences among Six salmonella serovars in abilities to colonize reproductive organs and to contaminate eggs in laying hens. Avian Dis 2001, 45:61-69.

17. Miyamoto T, Baba E, Tanaka T, Sasai K, Fukata T, Arakawa A: Salmonella enteritidis contamination of eggs from hens inoculated by vaginal, cloacal, and intravenous routes. Avian Dis 1997, 41:296-303.

18. Medici DD, Croci L, Delibato E, Di Pasquale S, Filetici E, Toti L: Evaluation of DNA extraction methods for use in combination with SYBR green I realtime PCR to detect salmonella enterica serotype enteritidis in poultry. Appl Environ Microbiol 2003, 69:3456-3461

19. Edwards RA, Olsen GJ, Maloy SR: Comparative genomics of closely related salmonellae. Trends Microbiol 2002, 10:94-99.

20. Stanley J, Baquar N: Phylogenetics of salmonella enteritidis. Int J Food Microbiol 1994, 21:79-87.

21. Clavijo Rl, Loui C, Andersen GL, Riley LW, Lu S: Identification of genes associated with survival of salmonella enterica serovar enteritidis in chicken egg albumen. Appl Environ Microbiol 2006, 72:1055-1064.

22. Chu C, Hong SF, Tsai C, Lin WS, Liu TP, Ou JT: Comparative physical and genetic maps of the virulence plasmids of salmonella enterica serovar typhimurium, enteritidis, choleraesuis, and dublin. Infect Immun 1999, 67:2611-2614.

23. Malorny $B$, Bunge $C$, Helmuth R: A real-time PCR for the detection of salmonella enteritidis in poultry meat and consumption eggs. J Microbiol Methods 2007, 70:245-251.

24. Gast RK, Beard CW: Serological detection of experimental Salmonella enteritidis infections in laying hens. Avian Dis 1990, 34:721-728.

25. Bakshi CS, Singh VP, Malik M, Singh RK, Sharma B: 55 kb plasmid and virulence-associated genes are positively correlated with salmonella enteritidis pathogenicity in mice and chickens. Vet Res Commun 2003, 27:425-432.

26. Fan SJ, Li DF, Duan ZY, Yang N, Xu GY: Infection status of eggs after hens infected salmonella enteritidis through feed intake. China Poult 2012, 34:11-15.

27. Didierlaurent A, Sirard JC, Kraehenbuhl JP, Neutra MR: How the gut senses its content. Cell Microbiol 2002, 4:61-72.

28. Gast RK, Guraya R, Guard-Bouldin J, Holt PS, Moore RW: Colonization of specific regions of the reproductive tract and deposition at different locations inside eggs laid by hens infected with salmonella enteritidis or salmonella Heidelberg. Avian Dis 2007, 51:40-44.

29. Vazquez-Torres A, Jones-Carson J, Baumler AJ, Falkow S, Valdivia R, Brown W, Le M, Berggren R, Parks WT, Fang FC: Extraintestinal dissemination of salmonella by CD18-expressing phagocytes. Nature 1999, 401:804-808.

30. Cho S, Crisp NS, Maley JR, Evon KM, Younus M, Arshad MM, Lu S, Saeed AM: Experimental infection of egg-laying hens with salmonella enterica serovar enteritidis phage type 4 and its three mutants. J Poult Sci 2010, 47:190-195.

31. Gantois I, Eeckhaut V, Pasmans F, Haesebrouck F, Ducatelle R, Immerseel FV: A comparative study on the pathogenesis of egg contamination by different serotypes of salmonella. Avian Pathol 2008, 37:399-406.

32. Fan JG, Zhong L, Xu ZJ, Tia LY, Ding XD, Li MS, Wang GL: Effects of lowcalorie diet on steatohepatitis in rats with obesity and hyperlipidemia. World J Gastroenterol 2003, 9:2045-2049.

33. Gast RK, Holt PS: Deposition of phage type 4 and 13a Salmonella enteritidis strains in the yolk and albumen of eggs laid by experimentally infected hens. Avian Dis 2000, 44:706-710.

34. Buck JD, Immerseel FV, Haesebrouck F, Ducatelle R: Colonization of the chicken reproductive tract and egg contamination by salmonella. J Appl Microbiol 2004, 97:233-245.

35. Gast RK, Jean GP, Peter SH: Effect of prior serial In vivo passage on the frequency of salmonella enteritidis contamination in eggs from experimentally infected laying hens. Avian Dis 2003, 47:633-639.
36. Miyamoto T, Horie T, Fukata T, Sasai K, Baba E: Changes in microflora of the cloaca and oviduct of hens after intracloacal or intravaginal inoculation with salmonella enteritidis. Avian Dis 1998, 42:536-544.

37. Singh A, Korasapati NR, Juneja VK, Subbiah J, Froning G, Thippareddi H: Dynamic predictive model for the growth of salmonella spp. in liquid whole egg. J Food Sci 2011, 76:M225-M232.

38. Gast RK, Guard-Bouldin J, Holt PS: The relationship between the duration of fecal shedding and the production of contaminated eggs by laying hens infected with strains of salmonella enteritidis and salmonella Heidelberg. Avian Dis 2005, 49:382-386.

39. Hughey $V L$, Johnson EA: Antimicrobial activity of lysozyme against bacteria involved in food spoilage and food-borne disease. Appl Environ Microbiol 1987, 53:2165-2170.

40. Lu S, Killoran PB, Riley LW: Association of salmonella enterica serovar enteritidis yafD with resistance to chicken egg albumen. Infect Immun 2003, 71:6734-6741.

41. Mayes FJ, Takeballi MA: Microbial contamination of the hen's egg: a review. J Food Prot 1983, 46:1092-1098.

42. Gast RK, Beard CW: Production of salmonella enteritidis-contaminated eggs by experimentally infected hens. Avian Dis 1990, 34:438-446.

43. Mann K: Proteomic analysis of the chicken egg vitelline membrane. Proteomics 2008, 8:2322-2332.

44. Reu KD, Grijspeerdt K, Messens W, Heyndrickx M, Uyttendaele M, Debevere J, Herman L: Eggshell factors influencing eggshell penetration and whole egg contamination by different bacteria, including salmonella enteritidis. Int J Food Microbiol 2006, 112:253-260.

45. Jones D, Anderson K, Curtis P, Jones F: Microbial contamination in inoculated shell eggs: I. Effects of layer strain and hen age. Poult Sci 2002, 81:715-720.

46. Humphrey TJ, Whitehead A, Gawler AHL, Henley A, Rowe B: Numbers of salmonella enteritidis in the contents of naturally contaminated hens' eggs. Epidemiol Infect 1991, 106:489-496.

47. Humphrey TJ, Whitehead A: Egg age and the growth of salmonella enteritidis PT4 in egg contents. Epidemiol Infect 1993, 111:209-220.

48. Duboccage L, Heyndrickx M, Grijspeerdt K, Herman L: Growth of salmonella in egg white. Meded Rijksuniv Gent Fak Landbouwkd Toegep Biol Wet 2001, 66:531-534.

49. Gast RK, Holt PS: Influence of the level and location of contamination on the multiplication of salmonella enteritidis at different storage temperatures in experimentally inoculated eggs. Poult Sci 2000, 79:559-563.

50. Messens W, Duboccage L, Grijspeerdt K, Heyndrickx M, Herman L: Growth of salmonella serovars in hens' egg albumen as affected by storage prior to inoculation. Food Microbiol 2004, 21:25-32.

doi:10.1186/2049-1891-5-4

Cite this article as: Fan et al:: The influences of SE infection on layers' production performance, egg quality and blood biochemical indicators. Journal of Animal Science and Biotechnology 2014 5:4.

\section{Submit your next manuscript to BioMed Central and take full advantage of:}

- Convenient online submission

- Thorough peer review

- No space constraints or color figure charges

- Immediate publication on acceptance

- Inclusion in PubMed, CAS, Scopus and Google Scholar

- Research which is freely available for redistribution 